\title{
Analysis on Characteristics and Development Strategies of Cultural Enterprises
}

\author{
Chunxin $\mathrm{Yu}$ \\ Shandong Yingcai University, Ji'nan, 250003, China
}

Keywords: Cultural enterprise, Characteristic, Development

\begin{abstract}
With the arrival of the era of knowledge economy, integrated development of cultural enterprises brought forth more opportunities and challenges to cultural enterprises. Considering particularity of cultural enterprises, besides material resources, these enterprises lay more importance on product brand effect and social consumption feature, so as to improve their market competitiveness. In this paper, the author combined relevant conditions of market economic development, proposed characteristics of cultural enterprises, and analyzed and stated their development strategies, so as to realize sustainable development of cultural enterprises.
\end{abstract}

\section{Introduction}

Compare with excellent cultural enterprises in foreign countries, Chinese cultural enterprises are characterized with small size, insufficient economic strength and obviously laggard market competitiveness. With quickened pace of global economic integration, it becomes inevitable for openness of Chinese cultural enterprises. At the same time, such integration also brought forth challenges to survival and development of Chinese cultural enterprises. How to improve core competitiveness and promote comprehensive development of cultural enterprises becomes a topic that we have to think about.

\section{Analysis on Characteristics of Cultural Enterprises}

In short, so-called "cultural enterprises" refer to those profit organizations providing cultural services and cultural products. A cultural enterprise has the process from investment to output in ordinary enterprises. Besides, it also obtains economic benefits from this process. Therefore, it also has certain uniqueness. Compared with enterprises in other types, cultural enterprises are of low dependence on material resources. Most cultural enterprises convert cultural resources to realize their development goals. A specific analysis is made on characteristics of cultural enterprises:

The characteristic of virtual resources

With cultural resources as the subject, cultural enterprises are of low dependence on material resources and high dependence on intangible thoughts and virtual resources. To some extent, this characteristic decides development characteristics of cultural enterprises. With film-making enterprises as an example, these enterprises have less fixed assets. However, scriptwriters, directors, performers and publishers are mainly responsible for value creation. In cultural enterprises, human ability and intelligence are mainly used to realize benefit goals.

The characteristic of productivity

Culture has economic attribute. At the same time, culture also emphasizes economic benefit. Culture is superstructure all the time. Its concentrated reflection is the reaction of superstructure for economic foundation. With quickened pace of global economic integration, the status of culture is increasingly improved. It has already become an important indicator used to measure the development level of a country. At the same time, culture also enters market competition with certain goals according to law of value. As a kind of special productivity, culture has common characteristics of productivity, including human nature, materiality and value nature. At the same time, culture also has unique attributes, such as immateriality, national character and nature of ideology. Development 
of cultural productivity is aimed at meeting increasingly enriched human demands for spiritual life, which is concentrated reflection of social civilization and progress.

\section{The characteristic of human resources}

Talent is served as core competitiveness of cultural enterprises. Information and knowledge are the most important production elements, especially for culture, technology and other intangible assets. Talent is served as the carrier of intangible assets. Its importance goes without saying. With animation enterprises as an example, an animation is finished by workers from conception to drawing and releasing. Once talents are insufficient, enterprise operation will suffer from great obstacle. However, brain drain in a certain link will cause losses to the entire animation. In the development process, therefore, cultural enterprises should pay attention to management and motivation of talents. While realizing the maximum benefits, cultural enterprises cannot abandon the carrier function of cultural inheritance.

Under the overall background of economic globalization, market economy is increasingly improved. As an industry in virtuous circle, cultural enterprises should convert investment into output and pursue for the maximum profits. This is compatible with socialist cultural development. At the same time, it is also beneficial for improvement to overall cultural level of China.

\section{Development Strategies for Cultural Enterprises}

\section{Quicken the pace of comprehensively deepened reform to cultural mechanism}

Firstly, governmental departments must quicken the function transformation process, and positively promote separation of government \& enterprises and separation of management and transaction. At the same time, cultural management organizations should make radical transformation with running of culture as the major task, promote innovations to cultural management mode, positively promote various cultural enterprises to realize updating of operation pattern, make public economy to develop toward stockholding system and mixing system, make continuous improvement to modern enterprise system, invest capitals in positively developing various approaches, promote competitive cultural enterprises to go out and participate in various activities, and make great efforts to improve enterprise influence. Secondly, relevant departments and organizations should promote the reform course of cultural mechanism, modify and perfect existing cultural policies by comprehensive innovation to operating pattern of cultural enterprises, promote the realization of sustainable development of the cultural market, always persist in the pattern mainly of cultural enterprises and aided by guidance of governmental departments, apply modern enterprise reform to form more standardized modern cultural enterprises, specify the subjective status of market, vigorously promote the reform of property relation system, form the mixing system of investment subjects as soon as possible, enhance supervision of cultural industry, and comprehensively construct a batch of modern cultural enterprises with innovation capability and market vitality.

\section{Realize sustainable development of cultural resources}

In the development stage of socialist market economy, sustainable development is the fundamental basis for improvement to enterprise vitality. To promote sustainable development of cultural enterprises, we must follow the principle of "promotion of priority resources", highlight characteristics of cultural enterprises, adapt to market orientation, and realize the integration of economic and social benefits. In the development process of current cultural enterprises, therefore, we should pay attention to the following aspects: (1) avoid quick success; in the development process of cultural enterprises, it is easy to produce the phenomenon of cultural bubble. Thus, it is necessary for cultural enterprises to be based on reality, set up the concept of sustainable development, and continuously dig cultural resources; (2) give play to the importance of planning; cultural enterprises should make great efforts to realize combination of cultural, social and economic benefits, make scientific decisions and plans, and realize goals of sustainable development; (3) transform from extensive operation into delicacy management; enhance guarantee from the perspective of legislation, avoid excessive development of cultural resources, and improve management level; this is a key factor for realization of sustainable development. For instance, scenic spots want more visitors. 
Considering limited reception capability, however, too many visitors are unfavorable for sustainable development of scenic spots. At the same time, it is unable to provide high-quality services to visitors; and (4) enhance foreign exchange and cooperation, positively refer to operating mechanism and development experience of excellent international cultural enterprises, and creatively utilize cultural resources.

\section{Model cultural enterprise brands}

In the era of market competition, brand advantage is a key factor of cultural enterprise development. Brand is a kind of intangible asset for culture as well as one of important elements for core competitiveness of enterprises. Enterprises can take a place in fierce market competition only by forming unique brand culture. At the same time, cultural enterprises should be brave in participating in competition in the international market. At present, most Chinese cultural enterprises have already realized the importance of brand. However, their competitiveness in the international market is obviously inadequate. To some extent, this also indicates low openness of cultural industry. Therefore, it is difficult to conform to development needs of market competition ${ }^{[1]}$. Only with proprietary intellectual property rights, Chinese cultural enterprises can take a place in the international market, and improve their competition, influence and emissive power at the same time.

Development of cultural enterprise brand will attract more loyal brand customers. This is the existence of its value. We should support enterprises to participate into market competition, and urge and supervise enterprises to practice marketing mix, so as to obtain stronger control force and development force. In the development process, therefore, Chinese cultural enterprises must lay emphasis on brand construction, realize compatible enterprise development with consumers' cultural demands, continuously improve product quality, and enhance the service level. At first, Chinese cultural enterprises should make reasonable brand and market orientation. So-called brand orientation is to promote cultural enterprises to set up unique images in market competition according to respective brand advantages, conform to customers' needs, deepen the brand into the mind of customers, and take a favorable place in the heart of customers. Cultural enterprises should pay attention to development and competition tendency in the consumer market, realize differentiated competitive tactics, and concentrate limited manpower, financial resources and material resources to lay a foundation for realization of brand strategy. To standing out, cultural enterprises must lay emphasis on the function of difference. The attention of customers can be attracted only by difference. Band orientation is a basic precondition for implementation of brand strategy. All marketing activities are under the influence of brand orientation. Secondly, we should research and develop different brands. To release brand products, enterprises must make market surveys, so as to master demand conditions of the customer market, and develop corresponding products. For different regions and different customers, consumer demands are also different. Thus, it requires cultural enterprises to make necessary market segmentation, understand conditions of various consumer groups, and dig more market opportunities. Thirdly, cultural enterprises should enhance brand protection, make it become the core of enterprise competitive development, and encourage construction of more enterprise cultures.

Before design of cultural products, we must select and design according to hobbies of customers, and display the most impressive points and those points with cultural characteristics. China has a long history of culture for more than five thousands of years. Modern cultural enterprises should comprehensively apply precious resources, and implement orientation of cultural products on the premise of a deep understanding of its connotation, so as to form new cultural products with more competitiveness and more attractive to customer groups. To expand their market shares and achieve continuous development in more and more fierce modern competition, cultural enterprises must form individualized brands with distinctive features. Thus, it is necessary for cultural enterprises to deepen studies, use for reference beneficial development experiences of foreign cultural industries, and introduce useful concepts, so as to positively promote development of cultural enterprises in China. Moreover, cultural enterprises should radically break through industrial and department limitations under planned economic system, comprehensively integrate various cultural resources, form 
competitive modern cultural enterprises and groups, and really apply creativity and individuality in developing a new road in the market, so as to improve sustainable development capacity of Chinese cultural enterprises.

\section{Implement social responsibilities of enterprises}

The same as ordinary enterprises, cultural enterprises are mainly for profit. Besides realization of economic goals, social responsibilities of enterprises cannot be neglected. In equity theory, the theory of interest related parities is embodied through social responsibilities of enterprises, especially for cultural enterprises. Social responsibility plays an important role of moral institution in social development, and reflects the value of social identity. Social responsibilities of cultural enterprises mainly include three parts: economic responsibility, social response and public responsibility. Cultural industrial products are used by people. More importantly, these products have an impact on people's values and values of thought. Vulgar culture will certainly bring forth spiritual pollution, with greater influence than environmental pollution. It may probably cause deep-level deficiency of humanistic connotation. For instance, some unhealthy audiovisual products, newspapers, periodicals and network junk information will have direct impacts on people, especially unfavorable for teenagers' physical and psychological health and growth. Besides realization of economic goals, therefore, cultural enterprises should shoulder the mission of social responsibilities, promote construction and development of social civilization, and set up excellent enterprise cultures [2]. With China's access to WTO, transnational cultural groups have already stepped into China from various fields. Whether China can continuously maintain excellent cultural traditions and values is of great significance for realization of the goal of "powerful cultural country". At the same time, it can also promote sustainable development of cultural enterprises, and realize social benefits.

\section{Intensify development efficiency of cultural resources}

Innovation is the basis for resource development in cultural enterprises. At the same time, it is also a major approach for promotion of development of cultural enterprises. At present, innovation ability has already become an important factor for improvement to comprehensive national strength. For the purpose of development, cultural enterprises should make innovations to philosophies and develop relevant activities under the guidance of innovative philosophies. Only resources continuously adapt to market development needs, cultural enterprises can really form cultural effect, realize optimized allocation of resources, and improve cultural values. Innovation is served as the fundamental impetus used to promote cultural resource conversion and industrial development, realize brand effect, form influential industrial chains, and promote cultural market development with distinctive characteristics and creativity. To promote innovative development of cultural enterprises, we must break through traditional talent development pattern, and create design, content, subject and plan with innovative thought and practical capability. Such creation of cultural resources is to restructure and combine different contents, produce more cultural products with quality value, and support development of cultural enterprises.

Moreover, cultural enterprises should give play to the important role of innovation, continuously improve innovation capability, realize combination of innovative ideas with market development, realize combination of excellent historical and cultural resources with modern cultural resources, realize combination of international development with characteristics of China, positively introduce excellent innovation outcomes, enhance optimization and integration capability of cultural resources, and promote smooth development of cultural industry. Additionally, development of cultural industry emphasizes creativity of cultural resources. To obtain long-term development, Chinese cultural enterprises must get rid of the quiet sate all the time, break through the bottleneck, enhance respect for and emphasis on creativity, give more development space to original cultural products, and embody real values. At the same time, development of cultural products and cultural services must be based on market demands and customers' demands and good at applying new ideas, new arts and new thoughts into cultural products and cultural services. Only in this way, potential of cultural products and cultural services can be maximized, so as to meet people's increasingly growing demands for material culture and spiritual culture. 


\section{Take full advantage of favorable policies for cultural industrial development}

We should reasonably apply the state and different regions in providing favorable policies for development of cultural enterprises. This is a beneficial opportunity to meet the public's spiritual and cultural needs. It is of great significance for optimization of enterprise management. Cultural enterprises should improve development initiative, recognize the current market situation, lay emphasis on introduction and cultivation of more excellent cultural operation management talents (i.e. cultural creation talents and cultural production talents), cultivate a batch of talents who understand economic knowledge and national policies, construct a team of cultural professional managers, and provide more intellectual supports to development of cultural enterprises.

\section{Conclusion}

To really realize effectiveness of internal reform, cultural enterprises should strictly follow operating specifications for modern enterprises, realize independent management, achieve self-financing, develop various activities under great supports from the government, use for reference market cultural elements, realize organic combination of cultural products with cultural services, create independent cultural brands, and really improve market competitiveness of cultural enterprises.

\section{References}

[1] Zheng Zhiwu, Promotion of Cultural Legal Institution and Development of Small and Medium-sized Cultural Enterprises, Journal of Changsha University, 2009 (3);

[2] Ou Yangjian, Cultivation of Backbone Cultural Enterprises to Improve Culture Industry Quality, Academic Exploration, 2011 (3) 